\title{
Clinical management of severe acute respiratory infection (SARI) when COVID-19 disease is suspected. Interim guidance
}

Postępowanie kliniczne w ostrym zakażeniu dróg oddechowych o ciężkim przebiegu (SARI) w przypadku podejrzenia choroby COVID-19. Wytyczne tymczasowe

\section{March 2020}

I his is the second edition (version 1.2) of this document, which was originally adapted from Clinical management of severe acute respiratory infection when MERS-CoV infection is suspected (WHO, 2019).

It is intended for clinicians involved in the care of adult, pregnant, and paediatric patients with or at risk for severe acute respiratory infection (SARI) when infection with the COVID-19 virus is suspected. Considerations for paediatric patients and pregnant women are highlighted throughout the text. It is not meant to replace clinical judgment or specialist consultation but rather to strengthen clinical management of these patients and to provide up-to-date guidance. Best practices for infection prevention and control (IPC), triage and optimized supportive care are included.

This document is organized into the following sections:

1. Background

2. Screening and triage: early recognition of patients with SARI associated with COVID-19

3. Immediate implementation of appropriate IPC measures

4. Collection of specimens for laboratory diagnosis

5. Management of mild COVID-19: symptomatic treatment and monitoring

6. Management of severe COVID-19: oxygen therapy and monitoring

7. Management of severe COVID-19: treatment of co-infections

8. Management of critical COVID-19: acute respiratory distress syndrome (ARDS)

9. Management of critical illness and COVID-19: prevention of complications
10. Management of critical illness and COVID-19: septic shock

11. Adjunctive therapies for COVID-19: corticosteroids

12. Caring for pregnant women with COVID-19

13. Caring for infants and mothers with COVID-19: IPC and breastfeeding

14. Care for older persons with COVID-19

15. Clinical research and specific anti-COVID-19 treatments

Appendix: resources for supporting management of SARI in children.

These symbols are used to flag interventions:

Do: the intervention is beneficial (strong recommendation) $\mathbf{O R}$ the intervention is a best practice statement.

X Don't: the intervention is known to be harmful.

? Consider: the intervention may be beneficial in selected patients (conditional recommendation) OR be careful when considering this intervention.

This document provides clinicians with updated interim guidance on timely, effective, and safe supportive management of patients with suspected and confirmed COVID-19. The definitions of mild and severe illness are in Tab. 2 . Those with critical illness are defined as patients with acute respiratory distress syndrome (ARDS) or sepsis with acute organ dysfunction.

The recommendations in this document are derived from WHO publications. Where WHO guidance is not available, we refer to evidence-based guidelines. Members of a WHO 
global network of clinicians and clinicians who have treated patients with SARS, MERS, or severe influenza have reviewed the recommendations (see Acknowledgements). For queries, please e-mail: outbreak@who.int with “COVID-19 clinical question" in the subject line.

\section{BACKGROUND}

Coronavirus disease 2019 (COVID-19) is a respiratory tract infection caused by a newly emergent coronavirus, that was first recognized in Wuhan, China, in December 2019. Genetic sequencing of the virus suggests that it is a betacoronavirus closely linked to the SARS virus ${ }^{(1)}$.

While most people with COVID-19 develop only mild or uncomplicated illness, approximately $14 \%$ develop severe disease that requires hospitalization and oxygen support, and $5 \%$ require admission to an intensive care unit ${ }^{(1)}$. In severe cases, COVID-19 can be complicated by the acute respiratory distress syndrome (ARDS), sepsis and septic shock, multiorgan failure, including acute kidney injury and cardiac injury ${ }^{(2)}$. Older age and co-morbid disease have been reported as risk factors for death, and recent multivariable analysis confirmed older age, higher Sequential Organ Failure Assessment (SOFA) score and d-dimer $>1 \mu \mathrm{g} / \mathrm{L}$ on admission were associated with higher mortality. This study also observed a median duration of viral RNA detection of 20.0 days (interquartile range, IQR 17.0-24.0) in survivors, but COVID-19 virus was detectable until death in non-survivors. The longest observed duration of viral shedding in survivors was 37 days $^{(3,4)}$.

Building on evidence-informed guidelines developed by a multidisciplinary panel of health care providers with experience in the clinical management of patients with COVID-19 and other viral infections, including SARS and MERS, as well as sepsis and ARDS, this guidance should serve as a foundation for optimized supportive care to ensure the best possible chance for survival and to allow for reliable comparison of investigational therapeutic interventions as part of randomized controlled trials $^{(5,6)}$.

There are few data on the clinical presentation of COVID-19 in specific populations, such as children and pregnant women. In children with COVID-19 the symptoms are usually less severe than adults and present mainly with cough and fever, and co-infection has been observed ${ }^{(7,8)}$. Relatively few cases have been reported of infants confirmed with COVID-19; those experienced mild illness ${ }^{(9)}$. There is currently no known difference between the clinical manifestations adults of reproductive age. Pregnant and recently pregnant women with suspected or confirmed COVID-19 should be treated with supportive and management therapies, as described below, taking into account the immunologic and physiologic adaptations during and after pregnancy.

\section{SCREENING AND TRIAGE: EARLY RECOGNITION OF PATIENTS WITH SARI ASSOCIATED WITH COVID-19}

\begin{abstract}
$\sqrt{ } \mathrm{scr}$ Screening and triage: Screen and isolate all patients with suspected COVID-19 at the first point of contact with the health care system (such as the emergency department or outpatient department/clinic). Consider COVID-19 as a possible etiology of patients with acute respiratory illness under certain conditions (see Tab. 1). Triage patients using standardized triage tools and start first-line treatments.
\end{abstract}

Remark 1: Although the majority of people with COVID-19 have uncomplicated or mild illness (81\%), some will develop severe illness requiring oxygen therapy $(14 \%)$ and approximately $5 \%$ will require intensive care unit treatment. Of those critically ill, most will require mechanical ventilation ${ }^{(2,10)}$. The most common diagnosis in severe COVID-19 patients is severe pneumonia.

Remark 2: Early recognition of suspected patients allows for timely initiation of appropriate IPC measures (see Tab. 3). Early identification of those with severe illness, such as severe pneumonia (see Tab. 2), allows for optimized supportive care treatments and safe, rapid referral and admission to a designated hospital ward or intensive care unit according to institutional or national protocols.

Remark 3: Older patients and those with comorbidities, such as cardiovascular disease and diabetes mellitus, have increased risk of severe disease and mortality. They may

\begin{tabular}{|l|l|}
\hline $\begin{array}{l}\text { Surveillance case } \\
\text { definitions for } \\
\text { COVID-19* }\end{array}$ & $\begin{array}{l}\text { Suspect case } \\
\text { See latest WH0 case definitions for suspect } \\
\text { case of COVID-19*. } \\
\text { Confirmed case } \\
\text { A person with laboratory confirmation of } \\
\text { COVID-19 infection, irrespective of clinical } \\
\text { signs and symptoms. }\end{array}$ \\
\hline $\begin{array}{l}\text { * See Global Surveillance for human infection with coronavirus disease } \\
\text { (COVID-19) for latest case definitions. }\end{array}$ \\
\hline
\end{tabular}

Tab. 1. Definitions of SARI and surveillance case definitions for COVID-19* 


\begin{tabular}{|c|c|}
\hline Mild illness & $\begin{array}{l}\text { Patients uncomplicated upper respiratory tract viral infection may have non-specific symptoms such as fever, fatigue, cough (with or without } \\
\text { sputum production), anorexia, malaise, muscle pain, sore throat, dyspnea, nasal congestion, or headache. Rarely, patients may also present } \\
\text { with diarrhoea, nausea, and vomiting } \\
\text { The eldi-13). } \\
\text { pregnancy events, such as dyspnea, fever, GI-symptoms or fatigue, may overlap with COVID-19 symptoms. }\end{array}$ \\
\hline Pneumonia & $\begin{array}{l}\text { Adult with pneumonia but no signs of severe pneumonia and no need for supplemental oxygen. } \\
\text { Child with non-severe pneumonia who has cough or difficulty breathing + fast breathing: fast breathing (in breaths } / \text { min): }<2 \text { months: } \geq 60 \text {; } \\
2-11 \text { months: } \geq 50 ; 1-5 \text { years: } \geq 40 \text {, and no signs of severe pneumonia. }\end{array}$ \\
\hline $\begin{array}{l}\text { Severe } \\
\text { pneumonia }\end{array}$ & $\begin{array}{l}\text { Adolescent or adult: fever or suspected respiratory infection, plus one of the following: respiratory rate }>30 \text { breaths/min; severe respiratory } \\
\text { distress; or } \mathrm{SpO}_{2} \leq 93 \% \text { on room air }{ }^{(2 d a p t e d ~ f r o m ~ 14)} \text {. } \\
\text { Child with cough or difficulty in breathing, plus at least one of the following: central cyanosis or } \mathrm{SpO}_{2}<90 \% \text {; severe respiratory distress } \\
\text { (e.g. grunting, very severe chest indrawing); signs of pneumonia with a general danger sign: inability to breastfeed or drink, lethargy or } \\
\text { unconsciousness, or convulsions }{ }^{(15)} \text {. Other signs of pneumonia may be present: chest indrawing, fast breathing (in breaths/min): }<2 \text { months: } \\
\geq 60 ; 2-11 \text { months: } \geq 50 ; 1-5 \text { years: } \geq 40^{(16)} \text {. While the diagnosis is made on clinical grounds; chest imaging may identify or exclude some } \\
\text { pulmonary complications. }\end{array}$ \\
\hline $\begin{array}{l}\text { Acute } \\
\text { respiratory } \\
\text { distress } \\
\text { syndrome } \\
\text { (ARDS) }^{(17-19)}\end{array}$ & 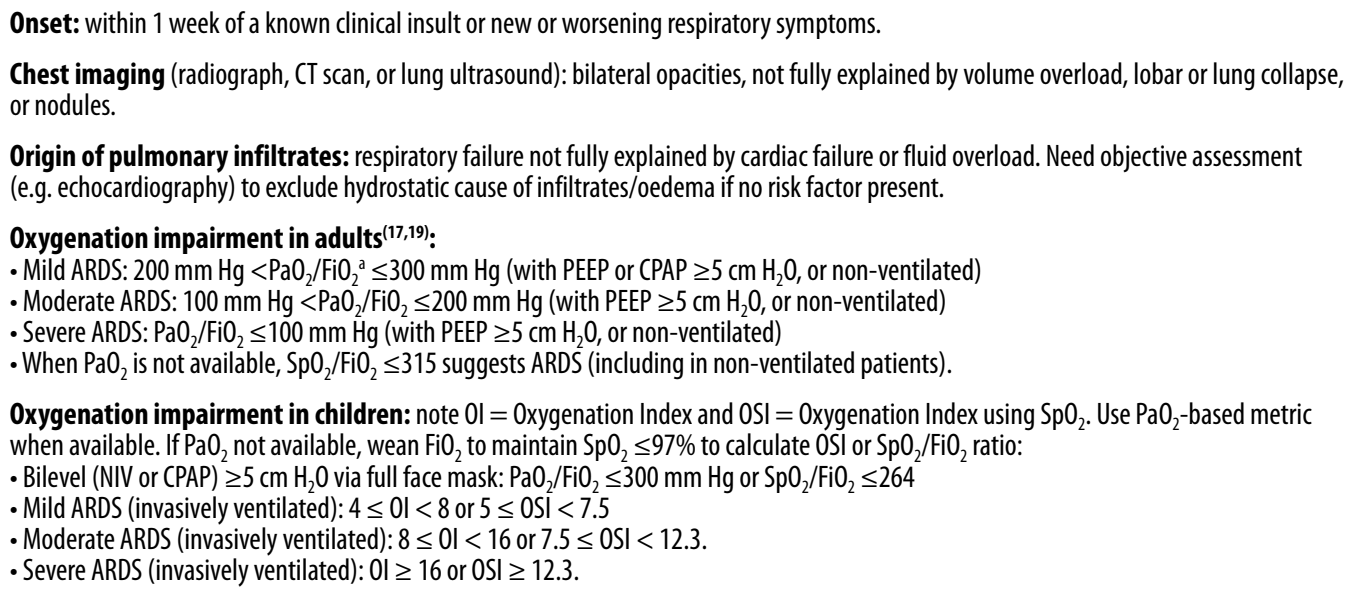 \\
\hline Sepsis ${ }^{(5,6)}$ & $\begin{array}{l}\text { Adults: life-threatening organ dysfunction caused by a dysregulated host response to suspected or proven infection }{ }^{b} \text {. Signs of organ } \\
\text { dysfunction include: altered mental status, difficult or fast breathing, low oxygen saturation, reduced urine output } t^{(5,20)} \text {, fast heart rate, weak } \\
\text { pulse, cold extremities or low blood pressure, skin mottling, or laboratory evidence of coagulopathy, thrombocytopenia, acidosis, high lactate, } \\
\text { or hyperbilirubinemia. } \\
\text { Children: suspected or proven infection and } \geq 2 \text { age-based systemic inflammatory response syndrome criteria, of which one must be } \\
\text { abnormal temperature or white blood cell count. }\end{array}$ \\
\hline Septic shock ${ }^{(5,6)}$ & $\begin{array}{l}\text { Adults: persisting hypotension despite volume resuscitation, requiring vasopressors to maintain MAP MAP } \geq 65 \mathrm{mmHg} \text { and serum lactate level } \\
>2 \mathrm{mmol} / \mathrm{L} \text {. } \\
\text { Children: any hypotension (SBP }<5^{\text {th }} \text { centile or }>2 \mathrm{SD} \text { below normal for age) or two or three of the following: altered mental state; } \\
\text { tachycardia or bradycardia ( } \mathrm{HR}<90 \mathrm{bpm} \text { or }>160 \mathrm{bpm} \text { in infants and } \mathrm{HR}<70 \mathrm{bpm} \text { or }>150 \mathrm{bpm} \text { in children); prolonged capillary refill } \\
\text { ( }>2 \mathrm{sec} \text { ) or feeble pulse; tachypnoea; mottled or cool skin or petechial or purpuric rash; increased lactate; oliguria; hyperthermia } \\
\text { or hypothermia }{ }^{211} \text {. }\end{array}$ \\
\hline \multicolumn{2}{|c|}{$\begin{array}{l}\text { a If altitude is higher than } 1000 \mathrm{~m} \text {, then correction factor should be calculated as follows: } \mathrm{PaO}_{2} / \mathrm{FiO}_{2} \times \text { barometric pressure/760. } \\
\text { ' }{ }^{\mathrm{b}} \text { The SOFA score ranges from } 0 \text { to } 24 \text { and includes points related to six organ systems: respiratory (hypoxemia defined by low } \mathrm{PaO}_{2} / \mathrm{FiO}_{2} \text { ); coagulation (low platelets); } \\
\text { liver (high bilirubin); cardiovascular (hypotension); central nervous system (low level of consciousness defined by Glasgow (oma Scale); and renal (low urine output } \\
\text { or high creatinine). Sepsis is defined by an increase in the sepsis-related SOFA score of } \geq 2 \text { points. Assume the baseline score is } 0 \text { if data are not available }{ }^{(22)} \text {. }\end{array}$} \\
\hline $\begin{array}{l}\text { Abbreviations: AR } \\
\text { oxygen; MAP - m } \\
\text { of oxygen; PEEP - } \\
\text { SOFA - sequentia }\end{array}$ & 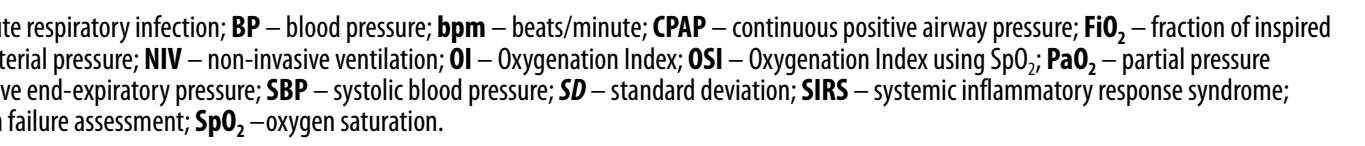 \\
\hline
\end{tabular}


present with mild symptoms but have high risk of deterioration and should be admitted to a designated unit for close monitoring.

Remark 4: For those with mild illness, hospitalization may not be required unless there is concern about rapid deterioration or an inability to promptly return to hospital, but isolation to contain/mitigate virus transmission should be prioritized. All patients cared for outside hospital (i.e. at home or non-traditional settings) should be instructed to manage themselves appropriately according to local/regional public health protocols for home isolation and return to a designated COVID-19 hospital if they get worse (https://www. who.int/publications-detail/home-care-for-patients-withsuspected-novel-coronavirus-(ncov)-infection-presentingwith-mild-symptoms-and-management-of-contacts).

\section{IMMEDIATE IMPLEMENTATION OF APPROPRIATE IPC MEASURES}

IPC is a critical and integral part of clinical management of patients and WHO guidance is available (https://www. who.int/emergencies/diseases/novel-coronavirus-2019/ technical-guidance/infection-prevention-and-control).
Initiate IPC at the point of entry of the patient to hospital. Screening should be done at first point of contact at the emergency department or outpatient department/clinics. Suspected COVID-19 patients should be given a mask and directed to separate area. Keep at least $1 \mathrm{~m}$ distance between suspected patients.

Standard precautions should always be applied in all areas of health care facilities. Standard precautions include hand hygiene and the use of personal protective equipment (PPE) when in indirect and direct contact with patients' blood, body fluids, secretions (including respiratory secretions) and non-intact skin. Standard precautions also include prevention of needle-stick or sharps injury; safe waste management; cleaning and disinfection of equipment; and cleaning of the environment.

In addition to standard precautions, health care workers should do a point-of-care risk assessment at every patient contact to determine whether additional precautions (e.g. droplet, contact, or airborne) are required.

\section{Instructions for patients}

Give suspect patient a medical mask and direct patient to separate area - an isolation room if available. Keep at least $1 \mathrm{~m}$ distance between suspected patients and other patients. Instruct all patients to cover nose and mouth during coughing or sneezing with tissue or flexed elbow and perform hand hygiene after contact with respiratory secretions.

\section{Apply droplet precautions}

Droplet precautions prevent large droplet transmission of respiratory viruses. Use a medical mask if working within $1 \mathrm{~m}$ of the patient. Place patients in single rooms, or group together those with the same etiological diagnosis. If an etiological diagnosis is not possible, group patients with similar clinical diagnosis and based on epidemiological risk factors, with a spatial separation. When providing care in close contact with a patient with respiratory symptoms (e.g. coughing or sneezing), use eye protection (face mask or goggles), because sprays of secretions may occur. Limit patient movement within the institution and ensure that patients wear medical masks when outside their rooms.

\section{Apply contact precautions}

Contact precautions prevent direct or indirect transmission from contact with contaminated surfaces or equipment (i.e. contact with contaminated oxygen tubing/ interfaces). Use PPE (medical mask, eye protection, gloves and gown) when entering room and remove PPE when leaving and practise hand hygiene after PPE removal. If possible, use either disposable or dedicated equipment (e.g. stethoscopes, blood pressure cuffs, pulse oximeters, and thermometers). If equipment needs to be shared among patients, clean and disinfect between each patient use. Ensure that health care workers refrain from touching their eyes, nose, and mouth with potentially contaminated gloved or ungloved hands. Avoid contaminating environmental surfaces that are not directly related to patient care (e.g. door handles and light switches). Avoid medically unnecessary movement of patients or transport. Perform hand hygiene.

\section{Apply airborne precautions when performing an aerosol-generating procedure}

Ensure that health care workers performing aerosol-generating procedures (e.g. open suctioning of respiratory tract, intubation, bronchoscopy, cardiopulmonary resuscitation) use the appropriate PPE, including gloves, long-sleeved gowns, eye protection, and fit-tested particulate respirators (N95 or equivalent, or higher level of protection). A scheduled fit test should not be confused with a user's'seal check before each use. Whenever possible, use adequately ventilated single rooms when performing aerosol-generating procedures, meaning negative pressure rooms with a minimum of 12 air changes per hour or at least $160 \mathrm{~L} / \mathrm{sec} /$ patient in facilities with natural ventilation. Avoid the presence of unnecessary persons individuals in the room. Care for the patient in the same type of room after mechanical ventilation begins. commences.

Abbreviations: ARI - acute respiratory infection; PPE - personal protective equipment. 


\section{COLLECTION OF SPECIMENS FOR LABORATORY DIAGNOSIS}

WHO guidance on specimen collection, processing and laboratory testing is available (https://www.who.int/ publications-detail/laboratory-testing-for-2019-novel-coronavirus-in-suspected-human-cases-20200117). Additionally, guidance on related biosafety procedures is available (https://apps.who.int/iris/bitstream/handle/10665/331138/WHO-WPE-GIH-2020.1-eng.pdf).

Collect blood cultures for bacteria that cause pneumonia and sepsis, ideally before antimicrobial therapy. DO NOT delay antimicrobial therapy to collect blood cultures.

Collect specimens from the upper respiratory tract (URT; nasopharyngeal and oropharyngeal) AND, where clinical suspicion remains and URT specimens are negative, collect specimens from the lower respiratory tract when readily available (LRT; expectorated sputum, endotracheal aspirate, or bronchoalveolar lavage in ventilated patient) for COVID-19 virus testing by RT-PCR and bacterial stains/cultures.

In hospitalized patients with confirmed COVID-19, repeated URT and LRT samples can be collected to demonstrate viral clearance. The frequency of specimen collection will depend on local epidemic characteristics and resources. For hospital discharge, in a clinically recovered patient, two negative tests, at least 24 hours apart, is recommended.

Remark 1: Use appropriate PPE for specimen collection (droplet and contact precautions for URT specimens; airborne precautions for LRT specimens). When collecting URT samples, use viral swabs (sterile Dacron or rayon, not cotton) and viral transport media. Do not sample the nostrils or tonsils. In a patient with suspected COVID-19, especially with pneumonia or severe illness, a single URT sample does not exclude the diagnosis, and additional URT and LRT samples are recommended. LRT (vs. URT) samples are more likely to be positive and for a longer period ${ }^{(23)}$. Clinicians may elect to collect only LRT samples when these are readily available (for example, in mechanically ventilated patients). Sputum induction should be avoided owing to increased risk of aerosol transmission.

Remark 2 for pregnant patients: COVID-19 testing of symptomatic pregnant women may need to be prioritized to enable access to specialized care.

Remark 3: Dual infections with other respiratory viral and bacterial infections have been found in SARS, MERS and COVID-19 patients $^{(8)}$. As a result, a positive test for a non-COVID-19 pathogen does not rule out COVID-19. At this stage, detailed microbiologic studies are needed in all suspected cases. Both URT and LRT specimens can be tested for other respiratory viruses, such as influenza A and B (including zoonotic influenza A), respiratory syncytial virus, parainfluenza viruses, rhinoviruses, adenoviruses, enteroviruses (e.g. EVD68), human metapneumovirus and endemic human coronaviruses (i.e. HKU1, OC43, NL63, and 229E). LRT specimens can also be tested for bacterial pathogens, including Legionella pneumophila. In malaria-endemic areas, patients with fever should be tested for the presence of malaria or other co-infections with validated rapid diagnostic tests (RDTs) or thick and thin blood films and treated as appropriate. In endemic settings arbovirus infection (dengue/chikungunya) should also be considered in the differential diagnosis of undifferentiated febrile illness, particularly when thrombocytopenia is present. Co-infection with COVID-19 virus may also occur and a positive diagnostic test for dengue (e.g. dengue RDTs) does not exclude the testing for COVID-19 $9^{(24)}$.

\section{MANAGEMENT OF MILD COVID-19: SYMPTOMATIC TREATMENT AND MONITORING}

Patients with mild disease do not require hospital interventions, but isolation is necessary to contain virus transmission and will depend on national strategy and resources.

Remark: Although most patients with mild disease may not have indications for hospitalization, it is necessary to implement appropriate IPC to contain and mitigate transmission. This can be done either in hospital, if there are only sporadic cases or small clusters, or in repurposed, non-traditional settings; or at home.

Provide patients with mild COVID-19 with symptomatic treatment such as antipyretics for fever.

Counsel patients with mild COVID-19 about signs and symptoms of complicated disease. If they develop any of these symptoms, they should seek urgent care through national referral systems.

\section{MANAGEMENT OF SEVERE COVID-19: OXYGEN THERAPY AND MONITORING}

$\checkmark$ Give supplemental oxygen therapy immediately to patients with SARI and respiratory distress, hypoxaemia or shock and target $\mathrm{SpO}_{2}>94 \%$. 
Remarks for adults: Adults with emergency signs (obstructed or absent breathing, severe respiratory distress, central cyanosis, shock, coma, or convulsions) should receive airway management and oxygen therapy during resuscitation to target $\mathrm{SpO}_{2} \geq 94 \%$. Initiate oxygen therapy at $5 \mathrm{~L} / \mathrm{min}$ and titrate flow rates to reach target $\mathrm{SpO}_{2} \geq 93 \%$ during resuscitation; or use face mask with reservoir bag (at $10-15 \mathrm{~L} / \mathrm{min}$ ) if patient in critical condition. Once patient is stable, the target is $>90 \%$ $\mathrm{SpO}_{2}$ in non-pregnant adults and $\geq 92-95 \%$ in pregnant patients ${ }^{(16,25)}$.

Remarks for children: Children with emergency signs (obstructed or absent breathing, severe respiratory distress, central cyanosis, shock, coma or convulsions) should receive airway management and oxygen therapy during resuscitation to target $\mathrm{SpO}_{2} \geq 94 \%$; otherwise, the target $\mathrm{SpO}_{2}$ is $\geq 90 \%{ }^{(25)}$. Use of nasal prongs or nasal cannula is preferred in young children, as they may be better tolerated.

Remark 3: All areas where patients with SARI are cared for should be equipped with pulse oximeters, functioning oxygen systems and disposable, single-use, oxygen-delivering interfaces (nasal cannula, nasal prongs, simple face mask, and mask with reservoir bag). See Appendix for details of resources.

$\checkmark$ Closely monitor patients with COVID-19 for signs of clinical deterioration, such as rapidly progressive respiratory failure and sepsis and respond immediately with supportive care interventions.

Remark 1: Patients hospitalized with COVID-19 require regular monitoring of vital signs and, where possible, utilization of medical early warning scores (e.g. NEWS2) that facilitate early recognition and escalation of treatment of the deteriorating patient ${ }^{(26)}$.

Remark 2: Haematology and biochemistry laboratory testing and ECG should be performed at admission and as clinically indicated to monitor for complications, such as acute liver injury, acute kidney injury, acute cardiac injury, or shock. Application of timely, effective, and safe supportive therapies is the cornerstone of therapy for patients who develop severe manifestations of COVID-19.

Remarks 3: After resuscitation and stabilization of the pregnant patient, then fetal well-being should be monitored.

Understand the patient's co-morbid condition(s) to tailor the management of critical illness.

Remark 1: Determine which chronic therapies should be continued and which therapies should be stopped tempo-
Use conservative fluid management in patients with SARI when there is no evidence of shock.

Remarks: Patients with SARI should be treated cautiously with intravenous fluids, because aggressive fluid resuscitation may worsen oxygenation, especially in settings where there is limited availability of mechanical ventilation ${ }^{(27)}$. This applies for care of children and adults.

\section{MANAGEMENT OF SEVERE COVID-19: TREATMENT OF CO-INFECTIONS}

Give empiric antimicrobials to treat all likely pathogens causing SARI and sepsis as soon as possible, within 1 hour of initial assessment for patients with sepsis.

Remark 1: Although the patient may be suspected to have COVID-19, administer appropriate empiric antimicrobials within 1 hour of identification of sepsis ${ }^{(5)}$. Empiric antibiotic treatment should be based on the clinical diagnosis [community-acquired pneumonia, health care -associated pneumonia (if infection was acquired in health care setting) or sepsis], local epidemiology and susceptibility data, and national treatment guidelines.

Remark 2: When there is ongoing local circulation of seasonal influenza, empiric therapy with a neuraminidase inhibitor should be considered for the treatment for patients with influenza or at risk for severe disease $^{(5)}$.

Empiric therapy should be de-escalated on the basis of microbiology results and clinical judgment.

\section{MANAGEMENT OF CRITICAL COVID-19: ACUTE RESPIRATORY DISTRESS SYNDROME (ARDS)}

Recognize severe hypoxemic respiratory failure when a patient with respiratory distress is failing to respond to standard oxygen therapy and prepare to provide advanced oxygen/ventilatory support.

Remarks: Patients may continue to have increased work of breathing or hypoxemia even when oxygen is delivered via a face mask with reservoir bag (flow rates of $10-15 \mathrm{~L} / \mathrm{min}$, which is typically the minimum flow required to maintain bag inflation; $\left.\mathrm{FiO}_{2} 0.60-0.95\right)$. Hypoxemic respiratory failure in ARDS commonly results from intrapulmonary 
ventilation-perfusion mismatch or shunt and usually requires mechanical ventilation ${ }^{(5)}$.

Endotracheal intubation should be performed by a trained and experienced provider using airborne precautions.

Remarks: Patients with ARDS, especially young children or those who are obese or pregnant, may desaturate quickly during intubation. Pre-oxygenate with $100 \% \mathrm{FiO}_{2}$ for 5 minutes, via a face mask with reservoir bag, bag-valve mask, HFNO or NIV. Rapid-sequence intubation is appropriate after an airway assessment that identifies no signs of difficult intubation ${ }^{(28-30)}$.

The following recommendations pertain to mechanically ventilated adults and paediatric patients with ARDS $^{(5,31)}$.

Implement mechanical ventilation using lower tidal volumes $(4-8 \mathrm{~mL} / \mathrm{kg}$ predicted body weight, $\mathrm{PBW}$ ) and lower inspiratory pressures (plateau pressure $<30 \mathrm{~cm} \mathrm{H}_{2} \mathrm{O}$ ).

Remarks for adults: This is a strong recommendation from a clinical guideline for patients with ARDS ${ }^{(5)}$, and is suggested for patients with sepsis-induced respiratory failure who do not meet ARDS criteria ${ }^{(5)}$. The initial tidal volume is $6 \mathrm{~mL} / \mathrm{kg}$ PBW; tidal volume up to $8 \mathrm{~mL} / \mathrm{kg}$ PBW is allowed if undesirable side effects occur (e.g. dyssynchrony, $\mathrm{pH}<7.15$ ). Permissive hypercapnia is permitted. Ventilator protocols are available ${ }^{(32)}$. The use of deep sedation may be required to control respiratory drive and achieve tidal volume targets.

Remarks for children: In children, a lower level of plateau pressure $\left(<28 \mathrm{~cm} \mathrm{H}_{2} \mathrm{O}\right)$ is targeted, and lower target of $\mathrm{pH}$ is permitted (7.15-7.30). Tidal volumes should be adapted to disease severity: 3-6 mL/kg PBW in the case of poor respiratory system compliance, and $5-8 \mathrm{~mL} / \mathrm{kg}$ PBW with better preserved compliance ${ }^{(31)}$.

In adult patients with severe ARDS, prone ventilation for 12-16 hours per day is recommended.

Remarks for adults and children: Application of prone ventilation is strongly recommended for adult patients, and may be considered for paediatric patients with severe ARDS but requires sufficient human resources and expertise to be performed safely; protocols (including videos) are available ${ }^{(33,34)}$ (https://www.nejm.org/doi/full/10.1056/ NEJMoa1214103).

Remark for pregnant women: There is little evidence on prone positioning in pregnant women. Pregnant women may benefit from being placed in the lateral decubitus position.
Use a conservative fluid management strategy for ARDS patients without tissue hypoperfusion.

Remarks for adults and children: This is a strong guideline recommendation ${ }^{(5)}$; the main effect is to shorten the duration of ventilation. See reference ${ }^{(35)}$ for details of a sample protocol.

\section{? In patients with moderate or severe ARDS, higher PEEP instead of lower PEEP is suggested.}

Remark 1: PEEP titration requires consideration of benefits (reducing atelectrauma and improving alveolar recruitment) vs. risks (end-inspiratory overdistension leading to lung injury and higher pulmonary vascular resistance). Tables are available to guide PEEP titration based on the $\mathrm{FiO}_{2}$ required to maintain $\mathrm{SpO}_{2}{ }^{(32)}$. In younger children, maximal PEEP rates are $15 \mathrm{~cm} \mathrm{H}_{2} \mathrm{O}$. Although high driving pressure (plateau pressure - PEEP) may more accurately predict increased mortality in ARDS compared with high tidal volume or plateau pressure ${ }^{(36)}$, data from RCTs of ventilation strategies that target driving pressure are not currently available.

Remark 2: A related intervention of recruitment manoeuvres (RMs) is delivered as episodic periods of high continuous positive airway pressure (CPAP) (30-40 $\mathrm{cm} \mathrm{H}_{2} \mathrm{O}$ ), progressive incremental increases in PEEP with constant driving pressure, or high driving pressure; considerations of benefits vs risks are similar. Higher PEEP and RMs were both conditionally recommended in a clinical practice guideline. For PEEP, the guideline considered an individual patient data meta-analysis ${ }^{(37)}$ of three RCTs. However, a subsequent RCT of high PEEP and prolonged high-pressure RMs showed harm, suggesting that the protocol in this RCT should be avoided $^{(38)}$. Monitoring of patients to identify those who respond to the initial application of higher PEEP or a different RM protocol and stopping these interventions in non-responders are suggested ${ }^{(39)}$.

In patients with moderate-severe $\mathrm{ARDS}\left(\mathrm{PaO}_{2} / \mathrm{FiO}_{2}\right.$ $<150$ ), neuromuscular blockade by continuous infusion should not be routinely used.

Remark: A trial found that this strategy improved survival in adult patients with severe ARDS $\left(\mathrm{PaO}_{2} / \mathrm{FiO}_{2}\right.$ $<150)$ without causing significant weakness ${ }^{(40)}$, but results of a recent larger trial found that use of neuromuscular blockade with high PEEP strategy was not associated with a survival benefit when compared with a light sedation strategy without neuromuscular block$\operatorname{ade}^{(41)}$. Continuous neuromuscular blockade may still be considered in patients with ARDS, both adults and children, in certain situations: ventilator dyssynchrony 
despite sedation, such that tidal volume limitation cannot be reliably achieved; or refractory hypoxemia or hypercapnia.

X Avoid disconnecting the patient from the ventilator, which results in loss of PEEP and atelectasis.

Use in-line catheters for airway suctioning and clamp endotracheal tube when disconnection is required (for example, transfer to a transport ventilator).

The following recommendations pertain to adult and paediatric patients with ARDS who are treated with non-invasive or high-flow oxygen systems.

? High-flow nasal oxygen (HFNO) should be used only in selected patients with hypoxemic respiratory failure.

? Non-invasive ventilation (NIV) should be used only in selected patients with hypoxemic respiratory failure.

\section{! Patients treated with either HFNO or NIV should be closely monitored for clinical deterioration.}

Remark 1: Adult HFNO systems can deliver $60 \mathrm{~L} / \mathrm{min}$ of gas flow and $\mathrm{FiO}_{2}$ up to 1.0. Paediatric circuits generally only handle up to $25 \mathrm{~L} / \mathrm{min}$, and many children will require an adult circuit to deliver adequate flow.

Remark 2: Because of uncertainty around the potential for aerosolization, HFO, NIV, including bubble CPAP, should be used with airborne precautions until further evaluation of safety can be completed.

Remark 3: Compared with standard oxygen therapy, HFNO reduces the need for intubation ${ }^{(42)}$. Patients with hypercapnia (exacerbation of obstructive lung disease, cardiogenic pulmonary oedema), hemodynamic instability, multiorgan failure, or abnormal mental status should generally not receive HFNO, although emerging data suggest that HFNO may be safe in patients with mild-moderate and non-worsening hypercapnia ${ }^{(42-44)}$. Patients receiving HFNO should be in a monitored setting and cared for by experienced personnel capable of performing endotracheal intubation in case the patient acutely deteriorates or does not improve after a short trial (about 1 hour). Evidence-based guidelines on HFNO do not exist, and reports on HFNO in patients infected with other coronaviruses are limited ${ }^{(44)}$

Remark 4: NIV guidelines make no recommendation on use in hypoxemic respiratory failure (apart from cardiogenic pulmonary oedema and postoperative respiratory failure) or pandemic viral illness (referring to studies of SARS and large tidal volumes, and injurious transpulmonary pressures. Limited data suggest a high failure rate in patients with other viral infections such as MERS-CoV who receive NIV $^{(45)}$.

Remark 5: Patients receiving a trial of NIV should be in a monitored setting and cared for by experienced personnel capable of performing endotracheal intubation in case the patient acutely deteriorates or does not improve after a short trial (about 1 hour). Patients with haemodynamic instability, multiorgan failure, or abnormal mental status should likely not receive NIV in place of other options such as invasive ventilation.

Remark 6: In situations where mechanical ventilation might not be available, bubble nasal CPAP may be used for newborns and children with severe hypoxemia, and may be a more readily available alternative in resource-limited settings $^{(46)}$.

The following recommendations pertain to adult and paediatric patients with ARDS in whom lung protective ventilation strategy fails.

In settings with access to expertise in extracorporeal membrane oxygenation (ECMO), consider referral of patients who have refractory hypoxemia despite lung protective ventilation.

Remarks for adult and children: An RCT of ECMO for adult patients with ARDS was stopped early and found no statistically significant difference in the primary outcome of 60-day mortality between ECMO and standard medical management (including prone positioning and neuromuscular blockade $)^{(47)}$. However, ECMO was associated with a reduced risk of the composite outcome of mortality and crossover to $\mathrm{ECMO}^{(47)}$, and a post hoc Bayesian analysis of this RCT showed that ECMO is very likely to reduce mortality across a range of prior assumptions ${ }^{(48)}$. In patients with MERS, ECMO vs. conventional treatment was associated with reduced mortality in a cohort study ${ }^{(49)}$. ECMO should be offered only in expert centres with a sufficient case volume to maintain expertise and that can apply the IPC measures required for adult and paediatric COVID-19 patients $^{(50,51)}$.

\section{MANAGEMENT OF CRITICAL ILLNESS AND COVID-19: PREVENTION OF COMPLICATIONS}

Implement the following interventions (Tab. 4) to prevent complications associated with critical illness. These interventions are based on Surviving Sepsis ${ }^{(5)}$ or other guidelines ${ }^{(52-55)}$, and are generally limited to feasible recommendations based on high-quality evidence. 


\section{MANAGEMENT OF CRITICAL ILLNESS AND COVID-19: SEPTIC SHOCK}

Recognize septic shock in adults when infection is suspected or confirmed AND vasopressors are needed to maintain mean arterial pressure (MAP) $\geq 65 \mathrm{~mm} \mathrm{Hg}$ AND lactate is $\geq 2 \mathrm{mmol} / \mathrm{L}$, in absence of hypovolemia.

Recognize septic shock in children with any hypotension [systolic blood pressure $(S B P)<5^{\text {th }}$ centile or $>2 S D$ below normal for age] or two or more of the following: altered mental state; bradycardia or tachycardia (HR $<90 \mathrm{bpm}$ or $>160 \mathrm{bpm}$ in infants and $H R<70 \mathrm{bpm}$ or $>150 \mathrm{bpm}$ in children); prolonged capillary refill ( $>2 \mathrm{sec}$ ) or feeble pulses; tachypnea; mottled or cold skin or petechial or purpuric rash; increased lactate; oliguria; hyperthermia or hypothermia.

Remark 1: In the absence of a lactate measurement, use blood pressure (i.e. MAP) and clinical signs of perfusion to define shock.

Remark 2: Standard care includes early recognition and the following treatments within 1 hour of recognition: antimicrobial therapy, and initiation of fluid bolus and vasopressors for hypotension ${ }^{(5)}$. The use of central venous and arterial catheters should be based on resource availability and individual patient needs. Detailed guidelines from the Surviving Sepsis Campaign and WHO are available for the management of septic shock in adults ${ }^{(5)}$ and children ${ }^{(6,16)}$. Alternate fluid regimens are suggested when caring for adults and children in resource-limited settings ${ }^{(56,57)}$.

The following recommendations pertain to resuscitation strategies for adult and paediatric patients with septic shock.

In resuscitation for septic shock in adults, give 250-500 $\mathrm{mL}$ crystalloid fluid as rapid bolus in first 15-30 minutes and reassess for signs of fluid overload after each bolus.

In resuscitation from septic shock in children, give $10-20 \mathrm{~mL} / \mathrm{kg}$ crystalloid fluid as a bolus in the first 30-60 minutes and reassess for signs of fluid after each bolus.

Fluid resuscitation may lead to volume overload, including respiratory failure, particularly with ARDS. If there is no response to fluid loading or signs of volume overload appear (e.g. jugular venous distension, crackles on lung auscultation, pulmonary oedema on imaging, or hepatomegaly in children), then reduce or discontinue fluid administration. This step is particularly important in patients with hypoxemic respiratory failure.

Remark 1: Crystalloids include normal saline and Ringer's lactate.

Remark 2: Determine need for additional fluid boluses $(250-500 \mathrm{~mL}$ in adults or $10-20 \mathrm{~mL} / \mathrm{kg}$ in children) based on clinical response and improvement of perfusion targets. Perfusion targets include MAP ( $>65 \mathrm{~mm} \mathrm{Hg}$ or age-appropriate targets in children), urine output $(>0.5 \mathrm{~mL} / \mathrm{kg} / \mathrm{hr}$ in adults, $1 \mathrm{~mL} / \mathrm{kg} / \mathrm{hr}$ in children), and improvement of skin mottling and extremity perfusion, capillary refill, heart rate, level of consciousness, and lactate.

Remark 3: Consider dynamic indices of volume responsiveness to guide volume administration beyond initial resuscitation based on local resources and experience ${ }^{(5)}$. These indices include passive leg raises, fluid challenges with serial stroke volume measurements, or variations in systolic pressure, pulse pressure, inferior vena cava size, or stroke volume in response to changes in intrathoracic pressure during mechanical ventilation.

Remark 4: In pregnant women, compression of the inferior vena cava can cause a decrease in venous return and cardiac preload and may result in hypotension. For this reason, pregnant women with sepsis and or septic shock may need to be placed in the lateral decubitus position to off-load the inferior vena cava ${ }^{(58)}$.

Remark 5: Clinical trials conducted in resource-limited studies comparing aggressive versus conservative fluid regimens suggest higher mortality in patients treated with aggressive fluid regimens ${ }^{(56,57)}$.

X Do not use hypotonic crystalloids, starches, or gelatins for resuscitation.

Remark 1: Starches are associated with an increased risk of death and acute kidney injury compared with crystalloids. The effects of gelatins are less clear, but they are more expensive than crystalloids ${ }^{(5,59)}$. Hypotonic (vs. isotonic) solutions are less effective at increasing intravascular volume. Surviving Sepsis also suggests albumin for resuscitation when patients require substantial amounts of crystalloids, but this conditional recommendation is based on low-quality evidence ${ }^{(5)}$.

In adults, administer vasopressors when shock persists during or after fluid resuscitation. The initial blood pressure target is MAP $\geq 65 \mathrm{~mm} \mathrm{Hg}$ in adults and improvement of markers of perfusion. 


\begin{tabular}{|c|c|}
\hline Anticipated outcome & Interventions \\
\hline $\begin{array}{l}\text { Reduce days of invasive mechanical } \\
\text { ventilation }\end{array}$ & $\begin{array}{l}\text { - Use weaning protocols that include daily assessment for readiness to breathe spontaneously. } \\
\text { - Minimize continuous or intermittent sedation, targeting specific titration endpoints (light sedation unless } \\
\text { contraindicated) or with daily interruption of continuous sedative infusions. }\end{array}$ \\
\hline $\begin{array}{l}\text { Reduce incidence of ventilator-associated } \\
\text { pneumonia }\end{array}$ & $\begin{array}{l}\text { - Oral intubation is preferable to nasal intubation in adolescents and adults. } \\
\text { - Keep patient in semi-recumbent position (head of bed elevation } 30-45^{\circ} \text { ). } \\
\text { - Use a closed suctioning system; periodically drain and discard condensate in tubing. } \\
\text { - Use a new ventilator circuit for each patient; once patient is ventilated, change circuit if it is soiled or damaged, but not } \\
\text { routinely. } \\
\text { - Change heat moisture exchanger when it malfunctions, when soiled, or every } 5-7 \text { days. }\end{array}$ \\
\hline $\begin{array}{l}\text { Reduce incidence of venous } \\
\text { thromboembolism }\end{array}$ & $\begin{array}{l}\text { - Use pharmacological prophylaxis (low molecular-weight heparin [preferred if available] or heparin } 5000 \text { units } \\
\text { subcutaneously twice daily) in adolescents and adults without contraindications. For those with contraindications, use } \\
\text { mechanical prophylaxis (intermittent pneumatic compression devices). }\end{array}$ \\
\hline $\begin{array}{l}\text { Reduce incidence of catheter-related } \\
\text { bloodstream infection }\end{array}$ & $\begin{array}{l}\text { - Use a checklist with completion verified by a real-time observer as reminder of each step needed for sterile } \\
\text { insertion and as a daily reminder to remove catheter if no longer needed. }\end{array}$ \\
\hline Reduce incidence of pressure ulcers & - Turn patient every 2 hours. \\
\hline $\begin{array}{l}\text { Reduce incidence of stress ulcers and } \\
\text { gastrointestinal (GI) bleeding }\end{array}$ & $\begin{array}{l}\text { - Give early enteral nutrition (within } 24-48 \text { hours of admission). } \\
\text { - Administer histamine-2 receptor blockers or proton-pump inhibitors in patients with risk factors for GI bleeding. } \\
\text { Risk factors for GI bleeding include mechanical ventilation for } \geq 48 \text { hours, coagulopathy, renal replacement therapy, } \\
\text { liver disease, multiple comorbidities, and higher organ failure score. }\end{array}$ \\
\hline Reduce incidence of ICU-related weakness & - Actively mobilize the patient early in the course of illness when safe to do so. \\
\hline
\end{tabular}

Tab. 4. Prevention of complications

In children administer vasopressors if:

1. Signs of shock such as altered mental state; bradycardia or tachycardia (HR $<90 \mathrm{bpm}$ or $>160 \mathrm{bpm}$ in infants and $H R<70$ bpm or $>150$ bpm in children); prolonged capillary refill ( $>2 \mathrm{sec}$ ) or feeble pulses; tachypnea; mottled or cool skin or petechial or purpuric rash; increased lactate; oliguria persists after two repeat boluses; or

2. age-appropriate blood pressure targets are not achieved; or

3. signs of fluid overload are apparent ${ }^{(6)}$.

If central venous catheters are not available, vasopressors can be given through a peripheral IV, but use a large vein and closely monitor for signs of extravasation and local tissue necrosis. If extravasation occurs, stop infusion. Vasopressors can also be administered through intraosseous needles.

If signs of poor perfusion and cardiac dysfunction persist despite achieving MAP target with fluids and vasopressors, consider an inotrope such as dobutamine.
Remark 1: Vasopressors (i.e. norepinephrine, epinephrine, vasopressin, and dopamine) are most safely given through a central venous catheter at a strictly controlled rate, but it is also possible to safely administer them via peripheral vein ${ }^{(60)}$ and intraosseous needle. Monitor blood pressure frequently and titrate the vasopressor to the minimum dose necessary to maintain perfusion and prevent side effects. A recent study suggests that in adults 65 years or older a MAP $60-65 \mathrm{~mm} \mathrm{Hg}$ target is equivalent to $\geq 65 \mathrm{~mm} \mathrm{Hg}^{(61)}$.

Remark 2: Norepinephrine is considered first-line treatment in adult patients; epinephrine or vasopressin can be added to achieve the MAP target. Because of the risk of tachyarrhythmia, reserve dopamine for selected patients with low risk of tachyarrhythmia or those with bradycardia.

Remark 3: In children, epinephrine is considered first-line treatment, while norepinephrine can be added if shock persists despite optimal dose of epinephrine.

Remark 4: No RCTs have compared dobutamine with placebo for clinical outcomes. 
Remark 5: See section 11 on adjunctive therapies for remarks on corticosteroids and sepsis.

\section{ADJUNCTIVE THERAPIES FOR COVID-19: CORTICOSTEROIDS}

$X$ Do not routinely give systemic corticosteroids for treatment of viral pneumonia outside clinical trials.

Remark 1: A systematic review of observational studies of corticosteroids administered to patients with SARS reported no survival benefit and possible harms (avascular necrosis, psychosis, diabetes, and delayed viral clearance $)^{(62)}$. A systematic review of observational studies in influenza found a higher risk of mortality and secondary infections with corticosteroids; the evidence was judged as very low to low quality owing to confounding by indication $^{(63)}$. A subsequent study that addressed this limitation by adjusting for time-varying confounders found no effect on mortality ${ }^{(64)}$. Finally, a recent study of patients receiving corticosteroids for MERS used a similar statistical approach and found no effect of corticosteroids on mortality but delayed LRT clearance of MERS-CoV ${ }^{(65)}$. Given the lack of effectiveness and possible harm, routine corticosteroids should be avoided unless they are indicated for another reason. Other reasons may include exacerbation of asthma or COPD, septic shock, and risk/ benefit analysis needs to be conducted for individual patients.

Remark 2: A recent guideline issued by an international panel and based on the findings of two recent large RCTs makes a conditional recommendation for corticosteroids for all patients with sepsis (including septic shock) ${ }^{(66)}$. Surviving Sepsis guidelines, written before these RCTs were reported, recommend corticosteroids only for patients in whom adequate fluids and vasopressor therapy do not restore hemodynamic stability ${ }^{(5)}$. Clinicians considering corticosteroids for a patient with COVID-19 and sepsis must balance the potential small reduction in mortality with the potential downside of prolonged shedding of coronavirus in the respiratory tract, as has been observed in patients with MERS ${ }^{(65)}$. If corticosteroids are prescribed, monitor and treat hyperglycaemia, hypernatraemia, and hypokalaemia. Monitor for recurrence of inflammation and signs of adrenal insufficiency after stopping corticosteroids, which may have to be tapered. Because of the risk of Strongyloides stercoralis hyper-infection with steroid therapy, diagnosis or empiric treatment should be considered in endemic areas if steroids are used ${ }^{(67)}$.

Remark 2 for pregnant women: WHO recommends antenatal corticosteroid therapy for women at risk of preterm birth from 24 to 34 weeks of gestation when there is no clinical evidence of maternal infection, and adequate childbirth and newborn care is available. However, in cases where the woman presents with mild COVID-19, the clinical benefits of antenatal corticosteroid might outweigh the risks of potential harm to the mother. In this situation, the balance of benefits and harms for the woman and the preterm newborn should be discussed with the woman to ensure an informed decision, as this assessment may vary depending on the woman's clinical condition, her wishes and that of her family, and available health care resources (https://www.who.int/reproductivehealth/publications/ maternal_perinatal_health/preterm-birth-highlights/en/).

Remark 3: WHO has prioritized the evaluation of corticosteroids in clinical trials to assess safety and efficacy (https://www.who.int/blueprint/priority-diseases/key-action/Global_Research_Forum_FINAL_VERSION_for_ web_14_feb_2020.pdf?ua=1).

\section{CARING FOR PREGNANT WOMEN WITH COVID-19}

To date, there are limited data on clinical presentation and perinatal outcomes after COVID-19 during pregnancy or the puerperium. There is no evidence that pregnant women present with different signs or symptoms or are at higher risk of severe illness. So far, there is no evidence on mother-to-child transmission when infection manifests in the third trimester, based on negative samples from amniotic fluid, cord blood, vaginal discharge, neonatal throat swabs or breastmilk. Similarly, evidence of increased severe maternal or neonatal outcomes is uncertain, and limited to infection in the third trimester, with some cases of premature rupture of membranes, fetal distress, and preterm birth reported ${ }^{(68,69)}$.

This section builds on existing recommendations from WHO on pregnancy and infectious diseases and provides additional remarks for the management of pregnant and recently pregnant women.

Considering asymptomatic transmission of COVID-19 may be possible in pregnant or recently pregnant women, as with the general population, all women with epidemiologic history of contact should be carefully monitored.

$\checkmark$ Pregnant women with suspected, probable, or confirmed COVID-19, including women who may need to spend time in isolation, should have access to woman-centred, respectful skilled care, including obstetric, fetal medicine and neonatal care, as well as mental health and psychosocial support, with readiness to care for maternal and neonatal complications. 
Remark 1: Appropriate IPC measures and prevention of complications as described above also apply to pregnant and recently pregnant women, including those with miscarriage, late pregnancy fetal loss, and postpartum/postabortion women. These IPC precautions should be applied for all interactions between an infected caregiver and a child.

Remark 2: Mode of birth should be individualized based on obstetric indications and the woman's preferences. WHO recommends that caesarean section should ideally be undertaken only when medically justified (https:// apps.who.int/iris/bitstream/handle/10665/161442/WHO_ RHR_15.02_eng.pdf?sequence=1).

Emergency delivery and pregnancy termination decisions are challenging and based on many factors such as gestational age, severity of maternal condition, and fetal viability and well-being.

Remark 3: Multidisciplinary consultations from obstetric, perinatal, neonatal and intensive care specialists are essential.

All recently pregnant women with COVID-19 or who have recovered from COVID-19 should be provided with information and counselling on safe infant feeding and appropriate IPC measures to prevent COVID-19 virus transmission.

At this point, there is no evidence that pregnant women present with increased risk of severe illness or fetal compromise. Pregnant and recently pregnant women who have recovered from COVID-19 should be enabled and encouraged to attend routine antenatal, postpartum, or postabortion care as appropriate. Additional care should be provided if there are any complications.

Remark 1: All pregnant women with or recovering from COVID-19 should be provided with counselling and information related to the potential risk of adverse pregnancy outcomes.

Remark 2: Women's choices and rights to sexual and reproductive health care should be respected regardless of COVID-19 status, including access to contraception and safe abortion to the full extent of the law.

\section{CARING FOR INFANTS AND MOTHERS WITH COVID-19: IPC AND BREASTFEEDING}

Relatively few cases have been reported of infants confirmed with COVID-19; those that have been reported experienced mild illness. No vertical transmission has been documented. Amniotic fluid from six mothers posi- their neonates who were delivered by caesarean section all tested negative for the COVID-19 virus by RT-PCR. Breastmilk samples from the mothers after the first lactation were also all negative for the COVID-19 virus ${ }^{(68,69)}$.

Breastfeeding protects against morbidity and death in the post-neonatal period and throughout infancy and childhood. The protective effect is particularly strong against infectious diseases that are prevented through both direct transfer of antibodies and other anti-infective factors and long-lasting transfer of immunological competence and memory. See WHO Essential Newborn Care and Breastfeeding (https://apps.who.int/iris/bitstream/handle/10665/107481/e79227.pdf). Therefore, standard infant feeding guidelines should be followed with appropriate precautions for IPC.

Infants born to mothers with suspected, probable, or confirmed COVID-19 should be fed according to standard infant feeding guidelines, while applying necessary precautions for IPC.

Remarks: Breastfeeding should be initiated within 1 hour of birth. Exclusive breastfeeding should continue for 6 months with timely introduction of adequate, safe and properly fed complementary foods at age 6 months, while continuing breastfeeding up to 2 years of age or beyond. Because there is a dose-response effect, in that earlier initiation of breastfeeding results in greater benefits, mothers who are not able to initiate breastfeeding during the first hour after delivery should still be supported to breastfeed as soon as they are able. This may be relevant to mothers who deliver by caesarean section, after an anaesthetic, or those who have medical instability that precludes initiation of breastfeeding within the first hour after birth. This recommendation is consistent with the Global Strategy for Infant and Young Child Feeding (https://apps.who.int/iris/bitstream/handle/10665/42590/9241562218.pdf), as endorsed by the Fifty-fifth World Health Assembly, in resolution WHA54.2 in 2002, to promote optimal feeding for all infants and young children.

As with all confirmed or suspected COVID-19 cases, symptomatic mothers who are breastfeeding or practising skin-to- skin contact or kangaroo mother care should practise respiratory hygiene, including during feeding (for example, use of a medical mask when near a child if the mother has respiratory symptoms), perform hand hygiene before and after contact with the child, and routinely clean and disinfect surfaces with which the symptomatic mother has been in contact.

Breastfeeding counselling, basic psychosocial support, and practical feeding support should be provided to all pregnant women and mothers with 
infants and young children, whether they or their infants and young children have suspected or confirmed COVID-19.

Remark 1: All mothers should receive practical support to enable them to initiate and establish breastfeeding and manage common breastfeeding difficulties, including IPC measures. This support should be provided by appropriately trained health care professionals and community-based lay and peer breastfeeding counsellors. See Guideline: Counselling of Women to Improve Breastfeeding Practices (https://apps.who.int/iris/bitstream/handle/10665/280133/9789241550468-eng.pdf) and the WHO Guideline: Protection, Promoting and Supporting Breastfeeding in Facilities Providing Maternity and Newborn Services (https://apps.who.int/iris/bitstream/handle/10665/259386/9789241550086-eng.pdf).

In situations when severe illness in a mother with COVID-19 or other complications prevents her from caring for her infant or prevents her from continuing direct breastfeeding, mothers should be encouraged and supported to express milk, and safely provide breastmilk to the infant, while applying appropriate IPC measures.

Remarks: In the event that the mother is too unwell to breastfeed or express breastmilk, explore the viability of relactation, wet nursing, donor human milk, or appropriate breastmilk substitutes, informed by cultural context, acceptability to the mother, and service availability. There should be no promotion of breastmilk substitutes, feeding bottles and teats, pacifiers or dummies in any part of facilities providing maternity and newborn services, or by any of the staff. Health facilities and their staff should not give feeding bottles and teats or other products within the scope of the International Code of Marketing of Breast-milk Substitutes and its subsequent related WHA resolutions, to breastfeeding infants. This recommendation is consistent with the WHO guidance Acceptable medical reasons for use of breast-milk substitutes (https:// apps.who.int/iris/bitstream/handle/10665/69938/WHO_ FCH_CAH_09.01_eng.pdf;jsessionid=709AE28402D49263C8DF6D50048A0E58? sequence $=1$ ).

Mothers and infants should be enabled to remain together and practise skin-to-skin contact, kangaroo mother care and to remain together and to practise rooming-in throughout the day and night, especially immediately after birth during establishment of breastfeeding, whether they or their infants have suspected, probable, or confirmed COVID-19.

Remarks: Minimizing disruption to breastfeeding during the stay in the facilities providing maternity and newborn services will require health care practices that enable a mother to breastfeed for as much, as frequently, and as long as she wishes. See WHO Guideline: Protection, Promoting and Supporting Breastfeeding in Facilities Providing Maternity and Newborn Services (https://apps.who.int/iris/bitstream/handle/10665/2593 86/9789241550086-eng.pdf).

Parents and caregivers who may need to be separated from their children, and children who may need to be separated from their primary caregivers, should have access to appropriately trained health or non-health workers for mental health and psychosocial support.

Remarks: Given the high prevalence of common mental disorders among women in the antenatal and postpartum period, and the acceptability of programmes aimed at them, interventions targeted to these women need to be more widely implemented. Prevention services should be available in addition to services that treat mental health difficulties. This recommendation is consistent with the IASC Reference group for Mental Health and Psychosocial Support in Emergency Setting 2020 Briefing note on addressing mental health and psychosocial aspects of COVID-19 outbreak - version 1.1 (https://interagencystandingcommittee.org/ system/files/2020-03/MHPSS \% 20COVID 19\%20 Briefing\%20Note\%202\%20March\%202020-English.pdf) and the Improving Early Childhood Development: WHO Guideline (https://www.who.int/publications-detail/ improving-early-childhood-development-who-guideline).

\section{CARING FOR OLDER PERSONS WITH COVID-19}

Older age and comorbid diseases such as diabetes and hypertension have been reported as a risk factor for death with people with COVID-19 ${ }^{(4)}$. Therefore, older people are at highest risk for fatality and are one of the most vulnerable populations. It is important to recognize that older people have the same rights as others to receive high-quality health care, including intensive care. Refer to the guidance Integrated care for older people (ICOPE) (https://www.who.int/ageing/publications/ icope-handbook/en/).

$\sqrt{ }$

For older people with probable or suspected COVID-19, provide person-centred assessment, including not only conventional history taking, but a thorough understanding of the person's life, values, priorities, and preferences for health management.

Ensure multidisciplinary collaboration among physicians, nurses, pharmacists, and other health care professionals in the decision-making process to address multimorbidity and functional decline. 
Remark 1: Physiological changes with age lead to declines in intrinsic capacity, manifested as malnutrition, cognitive decline, and depressive symptoms; those conditions should be managed comprehensively.

Early detection of inappropriate medication prescriptions is recommended to prevent adverse drug events and drug interactions for those being treated for COVID-19.

Remark 2: Older people are at greater risk of polypharmacy, as a result of newly prescribed medications, inadequate medication reconciliation, and a lack of coordination of care, all of which increases the risk of negative health consequences.

$\checkmark$ Involve caregivers and family members in decision-making and goal-setting throughout the management of older COVID-19 patients.

\section{CLINICAL RESEARCH AND SPECIFIC ANTI-COVID-19 TREATMENTS}

There is no current evidence to recommend any specific anti-COVID-19 treatment for patients with confirmed COVID-19. There are many ongoing clinical trials testing various potential antivirals; these are registered on https:// clinicaltrials.gov/ or on the Chinese Clinical Trial Registry (http://www.chictr.org.cn/abouten.aspx).

\section{$\sqrt{ }$ col} Collect standardized clinical data on all hospitalized patients to improve our understanding of the natural history of disease.

Remark 1: Contribute anonymized data to the WHO Global COVID-19 Clinical Data Platform; contact EDCARN@ who.int to get log-in credentials. Disaggregated data for children and pregnant women are needed.

Remark 2: There is an urgent need to collect standardized data for the clinical characterization of COVID-19 to better understand the natural history of disease with serial biological sampling. Clinical characterization research protocols are available (https://isaric.tghn.org/protocols/ severe-acute-respiratory-infection-data-tools/).

Investigational anti-COVID-19 therapeutics should be used only in approved, randomized, controlled trials.

Remark 1: Refer to the WHO R\&D Blueprint website for the most up-to-date prioritization of therapeutics (https:// www.who.int/blueprint/priority-diseases/key-action/ novel-coronavirus/en/).
Remark 2: Refer to the WHO Core Clinical Randomized Controlled Trial protocol for use in evaluating the efficacy and safety of investigational therapeutic agents in combination with standard of care for the treatment of hospitalized patients with novel coronavirus disease (COVID-19) (https://www.who.int/blueprint/priority-diseases/key-action/multicenter-adaptive-RCT-of-investigational-therapeutics-for-COVID-19.pdf?ua=1).

Remark 3: If conducting an RCT is not possible, then investigational therapeutics should be used under Monitored Emergency Use of Unregistered Interventions Framework (MEURI), until an RCT can be initiated (https://www.who. int/ethics/publications/infectious-disease-outbreaks/en/).

\section{Acknowledgements}

The original version of this document was developed in consultation with International Forum for Acute Care Trialists (InFACT), ISARIC and Surviving Sepsis Campaign. The following individuals contributed to or reviewed the current version. Confidentiality and declarations of interest were collected and reviewed. The methodology was reviewed with a representative of the WHO Guideline Review Committee.

\section{WHO}

Janet V Diaz (Lead), April Baller, William Fischer (consultant), Tom Fletcher (consultant), Mercedes Bonet Semenas, Anshu Banerjee, Jane Cunningham, Meg Doherty, Paul Nathan Ford, Laurence GrummerStrawn, Olufemi Oladapo, Lisa Rogers, Nigel Rollins, Maria Pura Solon, Marco Vitoria, Prinzo Weise, Wilson Were, Caron Kim, Anna Thorson, Maurice Bucagu, Anayda Portela, Yuka Sumi, Howard Sobel, Maria Van Kerkhove.

\section{UNICEF}

Maya Arii, Joseph Senesie, Diane Holland.

\section{Non-WHO experts:}

Neill Adhikari, Sunnybrook Health Sciences Centre and University of Toronto; Yaseen Arabi, King Saud Bin Abdulaziz University for Health Sciences, Saudi Arabia; Bin Cao, China-Japan Friendship Hospital, Capital Medical University, Beijing, China; Jake Dunning, Public Health England, UK; Rob Fowler, University of Toronto, Canada; Charles David Gomersall, The Chinese University of Hong Kong, Hong Kong SAR, China; David Hui, Chinese University of Hong Kong, Hong Kong SAR, China; Yae-Jean Kim, Sungkyunkwan University, Samsung Medical Center, Republic of Korea; Norio Ohmagari, WHO Collaborating Centre for Prevention, Preparedness and Response to Emerging Infectious Diseases, National Center for Global Health and Medicine Hospital Toyama, Tokyo, Japan; Yinzhong Shen, Shanghai Public Health Clinical Center, Fudan University, Shanghai, China; Tim Uyeki, Centers for Disease Control and Prevention, USA; Vu Quoc Dat, Hanoi Medical University, Viet Nam; Niranjan Kissoon, UBC \& BC Children's Hospital Professor in Critical Care, Vancouver Canada; Joāo Paulo Souza, Professor Titular de Saúde Pública, Universidade de São Paulo, Brazil; Pisake Lumbiganon, Director WHO Collaborating Centre for Research Synthesis in Reproductive Health Faculty of Medicine Khon Kaen University Khon Kaen, Thailand; Lucille Blumberg, National Institute for Communicable Diseases (NICD), South Africa; Arthur Kwizera, Department of Anaesthesia and Critical Care, Makerere University Kampala, Uganda. 


\section{Special thanks to the team that contributed to the writing of this document}

Caroline Quach-Thanh, University of Montréal, Canada; Patrice Savard, l'Université de Montréal, Canada; Jesse Papenburg, McGill University, Canada; Guillaume Poliquin, Public Health Agency of Canada, Canada; Samira Mubareka, Sunnybrook Hospital, Canada; Srinivas Murthy, University of British Columbia, Canada; Marianna Offner, Public Health Agency of Canada, Canada; Tracie Jones, Vancouver, British Columbia, Canada; Sarah Forgie, Stollery Children's Hospital, Canada; Susy Hota, University of Toronto, Canada; Gerald Evans, Queens University, Canada; Guillaume Emeriaud, CHU Sainte-Justine l'Université de Montréal, Canada;
Perry Gray, University of Manitoba, Canada; Todd Hatchette, Dalhousie University, Canada; Jim Strong, Public Health Agency of Canada, Canada; Titus Yeung, Vancouver General Hospital, Canada.

Special thanks also go to the WHO COVID-19 IPC Global Expert Panel for their input.

Originally issued in English by the World Health Organization under the title Clinical management of severe acute respiratory infection (SARI) when COVID-19 disease is suspected: Interim guidance V 1.2. in 13 March 2020. 


\section{APPENDIX: RESOURCES FOR SUPPORTING MANAGEMENT OF SEVERE ACUTE RESPIRATORY INFECTIONS IN CHILDREN}
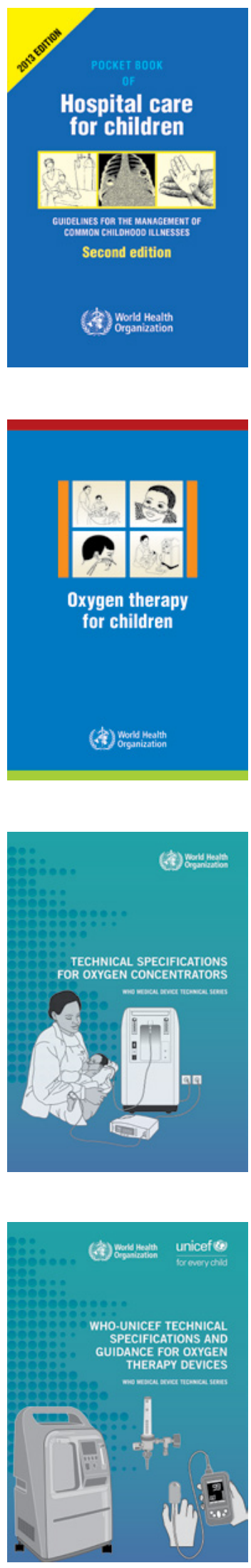

\section{Pocket Book of Hospital Care for Children: Guidelines for the Management of Common Childhood Illnesses (second edition) (2013)}

For use by doctors, nurses, and other health workers caring for children at first-level referral hospitals with basic laboratory facilities and essential medicines. These guidelines focus on the management of the major causes of childhood mortality in most developing countries, including pneumonia, and also cover common procedures, patient monitoring, and supportive care on the wards.

https://www.who.int/maternal_child_adolescent/documents/child_hospital_care/en/

\section{Oxygen Therapy for Children (2016)}

A bedside manual for health workers to guide the provision of oxygen therapy for children. The manual focuses on the availability and clinical use of oxygen therapy in children in health facilities to guide health workers, biomedical engineers, and administrators. It addresses detection of hypoxaemia, use of pulse oximetry, clinical use of oxygen, delivery systems, and monitoring of patients on oxygen therapy. The manual also addresses the practical use of pulse oximetry, and oxygen concentrators and cylinders.

http://www.who.int/maternal_child_adolescent/documents/child-oxygen-therapy/en/

Technical Specifications for Oxygen Concentrators (2015)

Provides an overview of oxygen concentrators and technical specifications to aid in selection, procurement, and quality assurance. It highlights the minimum performance requirements and technical characteristics for oxygen concentrators and related equipment that are suitable for the use in health facilities.

https://www.who.int/medical_devices/publications/tech_specs_oxygen-concentrators/en/

WHO-UNICEF Technical Specifications and Guidance for Oxygen Therapy Devices (2019)

The purpose of this document is to increase access to quality products to ensure the supply of oxygen, especially in low- and middle-income countries and low-resource settings within countries from all income groups. It aims to support ministries of health to ensure that oxygen supply is available, as well as to raise awareness of the importance of appropriate selection, procurement, maintenance, and use of medical devices, both capital equipment and single-use devices.

https://www.who.int/medical_devices/publications/tech_specs_oxygen_therapy_devices/en/ 


\section{References}

1. The Novel Coronavirus Pneumonia Emergency Response Epidemiology Team: Vital surveillances: the epidemiological characteristics of an outbreak of 2019 novel coronavirus diseases (COVID-19) China, 2020. China CDC Weekly 2020; 2: 113-122.

2. Yang X, Yu Y, Xu J et al.: Clinical course and outcomes of critically ill patients with SARS-CoV-2 pneumonia in Wuhan, China a single-centered, retrospective, observational study. Lancet Respir Med 2020; 8: 475-481.

3. Huang C, Wang Y, Li X et al.: Clinical features of patients infected with 2019 novel coronavirus in Wuhan, China. Lancet 2020; 395: 497-506.

4. Zhou F, Yu T, Du R et al.: Clinical course and risk factors for mortality of adult inpatients with COVID-19 in Wuhan, China: a retrospective cohort study. Lancet 2020; 395: 1054-1062.

5. Rhodes A, Evans LE, Alhazzani W et al.: Surviving Sepsis Campaign: International Guidelines for Management of Sepsis and Septic Shock: 2016. Intensive Care Med 2017; 43: 304-377.

6. Weiss SL, Peters MJ, Alhazzani W et al.: Surviving Sepsis Campaign International Guidelines for the Management of Septic Shock and Sepsis-Associated Organ Dysfunction in Children. Pediatr Crit Care Med 2020; 21: e52-e106.

7. Cai J, Xu J, Lin D et al.: A case series of children with 2019 novel coronavirus infection: clinical and epidemiological features. Clin Infect Dis 2020. pii: ciaa198.

8. Xia W, Shao J, Guo Y et al.: Clinical and CT features in pediatric patients with COVID-19 infection: different points from adults. Pediatr Pulmonol 2020; 55: 1169-1174.

9. Wei M, Yuan J, Liu Y et al.: Novel coronavirus infection in hospitalized infants under 1 year of age in China. JAMA 2020. DOI 10.1001/jama.2020.2131

10. Wu Z, McGoogan JM: Characteristics of and important lessons from the coronavirus disease 2019 (COVID-19) outbreak in China: summary of a report of 72314 cases from the Chinese Center for Disease Control and Prevention. JAMA 2020. DOI: 10.1001/jama.2020.2648.

11. Chen N, Zhou M, Dong X et al.: Epidemiological and clinical characteristics of 99 cases of 2019 novel coronavirus pneumonia in Wuhan, China: a descriptive study. Lancet 2020; 395: 507-513.

12. Guan WJ, Ni ZY, Hu Y et al.; China Medical Treatment Expert Group for Covid-19: Clinical characteristics of coronavirus disease 2019 in China. N Engl J Med 2020; 382: 1708-1720.

13. Wang D, Hu B, Hu C et al.: Clinical characteristics of 138 hospitalized patients with 2019 novel coronavirus-infected pneumonia in Wuhan, China. JAMA 2020. DOI: 10.1001/jama.2020.1585.

14. World Health Organization: Volume 2 IMAI District Clinician Manual. Hospital Care for Adolescents and Adults. World Health Organization, Geneva 2011. Available from: https://apps.who. int/iris/bitstream/handle/10665/77751/9789241548290_Vol2_ eng.pdf?sequence $=3$ [cited: 4 March 2020].

15. Russell FM, Reyburn R, Chan J et al.: Impact of the change in WHO's severe pneumonia case definition on hospitalized pneumonia epidemiology: case studies from six countries. Bull World Health Organ 2019; 97: 386-393.

16. World Health Organization: Pocket Book of Hospital Care for Children: Guidelines for the Management of Common Childhood Illnesses. World Health Organization, Geneva 2013. Available from: http://www.who.int/maternal_child_adolescent/documents/child_hospital_care/en/ [cited: 4 March 2020].

17. ARDS Definition Task Force; Ranieri VM, Rubenfeld GD, Thompson BT et al.: Acute respiratory distress syndrome: the Berlin Definition. JAMA 2012; 307: 2526-2533.

18. Khemani RG, Smith LS, Zimmerman JJ et al.; Pediatric Acute Lung Injury Consensus Conference Group: Pediatric acute respiratory distress syndrome: definition, incidence, and epidemiology: proceedings from the Pediatric Acute Lung Injury Consensus Conference. Pediatr Crit Care Med 2015; 16 (Suppl 1): S23-S40.

19. Riviello ED, Kiviri W, Twagirumugabe T et al.: Hospital incidence and outcomes of the acute respiratory distress syndrome using the Kigali modification of the Berlin definition. Am J Respir Crit Care Med 2016; 193: 52-59.

20. Goldstein B, Giroir B, Randolph A; International Consensus Conference on Pediatric Sepsis: International pediatric sepsis consensus conference: definitions for sepsis and organ dysfunction in pediatrics. Pediatr Crit Care Med 2005; 6: 2-8.

21. Davis AL, Carcillo JA, Aneja RK et al.: American College of Critical Care Medicine clinical practice parameters for hemodynamic support of pediatric and neonatal septic shock. Crit Care Med 2017; 45: 1061-1093.

22. Vincent JL, Moreno R, Takala J et al.: The SOFA (Sepsis-related Organ Failure Assessment) score to describe organ dysfunction/ failure. On behalf of the Working Group on Sepsis-Related Problems of the European Society of Intensive Care Medicine. Intensive Care Med 1996; 22: 707-710.

23. Park WB, Poon LLM, Choi SJ et al.: Replicative virus shedding in the respiratory tract of patients with Middle East respiratory syndrome coronavirus infection. Int J Infect Dis 2018; 72: 8-10.

24. Yan G, Lee CK, Lam LTM et al.: Covert COVID-19 and false-positive dengue serology in Singapore. Lancet Infect Dis 2020; 20: 536.

25. World Health Organization: Oxygen Therapy for Children: A Manual for Health Workers. World Health Organization, Geneva 2013. Available from: http://www.who.int/maternal_ child_adolescent/documents/child-oxygen-therapy/en/ [cited: 10 March 2020].

26. Abbott TE, Vaid N, Ip D et al.: A single-centre observational cohort study of admission National Early Warning Score (NEWS). Resuscitation 2015; 92: 89-93.

27. Schultz MJ, Dunser MW, Dondorp AM et al.; Global Intensive Care Working Group of the European Society of Intensive Care Medicine: Current challenges in the management of sepsis in ICUs in resource-poor settings and suggestions for the future. Intensive Care Med 2017; 43: 612-624.

28. Peng PWH, Ho PL, Hota SS: Outbreak of a new coronavirus: what anaesthetists should know. Br J Anaesth 2020; 124: 497-501.

29. Cheung JC, Ho LT, Cheng JV et al.: Staff safety during emergency airway management for COVID-19 in Hong Kong. Lancet Respir Med 2020; 8: e19.

30. Detsky ME, Jivraj N, Adhikari NK et al.: Will this patient be difficult to intubate? The rational clinical examination systematic review. JAMA 2019; 321: 493-503.

31. Rimensberger PC, Cheifetz IM; Pediatric Acute Lung Injury Consensus Conference Group: Ventilatory support in children with pediatric acute respiratory distress syndrome: proceedings from the Pediatric Acute Lung Injury Consensus Conference. Pediatr Crit Care Med 2015; 16 (Suppl 1): S51-S60.

32. NHLBI ARDS Network Tools [website]. Available from: http:// www.ardsnet.org/tools.shtml [cited: 4 March 2020].

33. Guérin C, Reignier J, Richard JC et al.; PROSEVA Study Group: Prone positioning in severe acute respiratory distress syndrome. N Engl J Med 2013; 368: 2159-2168.

34. Messerole E, Peine P, Wittkopp S et al.: The pragmatics of prone positioning. Am J Respir Crit Care Med 2002; 165: 1359-1363.

35. National Heart, Lung, and Blood Institute Acute Respiratory Distress Syndrome (ARDS) Clinical Trials Network; Wiedemann HP, Wheeler AP, Bernard GR et al.: Comparison of two fluid-management strategies in acute lung injury. N Engl J Med 2006; 354: 2564-2575.

36. Amato MB, Meade MO, Slutsky AS et al.: Driving pressure and survival in the acute respiratory distress syndrome. $\mathrm{N} \mathrm{Engl} \mathrm{J} \mathrm{Med}$ 2015; 372: 747-755.

37. Briel M, Meade M, Mercat A et al.: Higher vs lower positive end-expiratory pressure in patients with acute lung injury and acute respiratory distress syndrome: systematic review and meta-analysis. JAMA 2010; 303: 865-873.

38. Writing Group for the Alveolar Recruitment for Acute Respiratory Distress Syndrome Trial (ART) Investigators; Cavalcanti AB, Suzumura ÉA, Laranjeira LN et al.: Effect of lung recruitment and titrated positive end-expiratory pressure (PEEP) vs low PEEP on mortality in patients with acute respiratory distress syndrome: a randomized clinical trial. JAMA 2017; 318: 1335-1345.

39. Goligher EC, Kavanagh BP, Rubenfeld GD et al.: Oxygenation response to positive end-expiratory pressure predicts mortality in acute respiratory distress syndrome. A secondary analysis of the LOVS and ExPress trials. Am J Respir Crit Care Med 2014; 190: 70-76.

40. Papazian L, Forel JM, Gacouin A et al.: Neuromuscular blockers in early acute respiratory distress syndrome. N Engl J Med 2010; 363: $1107-1116$ 
41. National Heart, Lung, and Blood Institute PETAL Clinical Trials Network; Moss M, Huang DT, Brower RG et al.: Early neuromuscular blockade in the acute respiratory distress syndrome. $\mathrm{N} \mathrm{Engl}$ J Med 2019; 380: 1997-2008.

42. Rochwerg B, Brochard L, Elliott MW et al.: Official ERS/ATS clinical practice guidelines: noninvasive ventilation for acute respiratory failure. Eur Respir J 2017; 50. pii: 1602426.

43. Lee MK, Choi J, Park B et al.: High flow nasal cannulae oxygen therapy in acute-moderate hypercapnic respiratory failure. Clin Respir J 2018; 12: 2046-2056.

44. Luo Y, Ou R, Ling Y et al.: [The therapeutic effect of high flow nasal cannula oxygen therapy for the first imported case of Middle East respiratory syndrome to China]. Zhonghua Wei Zhong Bing Ji Jiu Yi Xue 2015; 27: 841-844.

45. Arabi YM, Arifi AA, Balkhy HH et al.: Clinical course and outcomes of critically ill patients with Middle East respiratory syndrome coronavirus infection. Ann Intern Med 2014; 160: 389-397.

46. Ekhaguere OA, Mairami AB, Kirpalani H: Risk and benefits of bubble continuous positive airway pressure for neonatal and childhood respiratory diseases in low- and middle-income countries. Paediatr Respir Rev 2019; 29: 31-36.

47. Combes A, Hajage D, Capellier G et al.; EOLIA Trial Group, REVA, and ECMONet: Extracorporeal membrane oxygenation for severe acute respiratory distress syndrome. N Engl J Med 2018; 378: 1965-1975.

48. Goligher EC, Tomlinson G, Hajage D et al.: Extracorporeal membrane oxygenation for severe acute respiratory distress syndrome and posterior probability of mortality benefit in a post hoc Bayesian analysis of a randomized clinical trial. JAMA 2018; 320: 2251-2259.

49. Alshahrani MS, Sindi A, Alshamsi F et al.: Extracorporeal membrane oxygenation for severe Middle East respiratory syndrome coronavirus. Ann Intensive Care 2018; 8: 3.

50. Combes A, Brodie D, Bartlett R et al.: Position paper for the organization of extracorporeal membrane oxygenation programs for acute respiratory failure in adult patients. Am J Respir Crit Care Med 2014; 190: 488-496.

51. Munshi L, Walkey A, Goligher E et al.: Venovenous extracorporeal membrane oxygenation for acute respiratory distress syndrome: a systematic review and meta-analysis. Lancet Respir Med 2019; 7: 163-172.

52. Klompas M, Branson R, Eichenwald EC et al.; Society for Healthcare Epidemiology of America (SHEA): Strategies to prevent ventilator-associated pneumonia in acute care hospitals: 2014 update. Infect Control Hosp Epidemiol 2014; 35: 915-936.

53. Marschall J, Mermel LA, Fakih M et al.; Society for Healthcare Epidemiology of America: Strategies to prevent central line-associated bloodstream infections in acute care hospitals: 2014 update. Infect Control Hosp Epidemiol 2014; 35: 753-771.

54. Muscedere J, Dodek P, Keenan S et al.; VAP Guidelines Committee and the Canadian Critical Care Trials Group: Comprehensive evidence-based clinical practice guidelines for ventilator-associated pneumonia: prevention. J Crit Care 2008; 23: 126-137.
55. Schmidt GA, Girard TD, Kress JP et al.; ATS/CHEST Ad Hoc Committee on Liberation from Mechanical Ventilation in Adults: Official executive summary of an American Thoracic Society/American College of Chest Physicians clinical practice guideline: liberation from mechanical ventilation in critically ill adults. Am J Respir Crit Care Med 2017; 195: 115-119.

56. Andrews B, Semler MW, Muchemwa L et al.: Effect of an early resuscitation protocol on in-hospital mortality among adults with sepsis and hypotension: a randomized clinical trial. JAMA 2017; 318: 1233-1240.

57. Maitland K, Kiguli S, Opoka RO et al.; FEAST Trial Group: Mortality after fluid bolus in African children with severe infection. N Engl J Med 2011; 364: 2483-2495.

58. Bridwell RE, Carius BM, Long B et al.: Sepsis in pregnancy: recognition and resuscitation. West J Emerg Med 2019; 20: 822-832.

59. Rochwerg B, Alhazzani W, Sindi A et al.; Fluids in Sepsis and Septic Shock Group: Fluid resuscitation in sepsis: a systematic review and network meta-analysis. Ann Intern Med 2014; 161: 347-355.

60. Loubani OM, Green RS: A systematic review of extravasation and local tissue injury from administration of vasopressors through peripheral intravenous catheters and central venous catheters. J Crit Care 2015; 30: 653.e9-653.e17.

61. Lamontagne F, Richards-Belle A, Thomas K et al.; 65 trial investigators: Effect of reduced exposure to vasopressors on 90-day mortality in older critically ill patients with vasodilatory hypotension: a randomized clinical trial. JAMA 2020. DOI: 10.1001/jama.2020.0930.

62. Stockman LJ, Bellamy R, Garner P: SARS: systematic review of treatment effects. PLoS Med 2006; 3: e343.

63. Rodrigo C, Leonardi-Bee J, Nguyen-Van-Tam J et al.: Corticosteroids as adjunctive therapy in the treatment of influenza. Cochrane Database Syst Rev 2016; 3: CD010406.

64. Delaney JW, Pinto R, Long J et al.; Canadian Critical Care Trials Group H1N1 Collaborative: The influence of corticosteroid treatment on the outcome of influenza A(H1N1pdm09)-related critical illness. Crit Care 2016; 20: 75.

65. Arabi YM, Mandourah Y, Al-Hameed F et al.; Saudi Critical Care Trial Group: Corticosteroid therapy for critically ill patients with Middle East respiratory syndrome. Am J Respir Crit Care Med 2018; 197: 757-767.

66. Lamontagne F, Rochwerg B, Lytvyn L et al.: Corticosteroid therapy for sepsis: a clinical practice guideline. BMJ 2018; 362: k3284.

67. Centers for Disease Control and Prevention: Resources for health professionals: parasites - strongyloides [website]. Centers for Disease Control and Prevention, Washington, DC. Available from: https://www.cdc.gov/parasites/strongyloides/health_professionals/index.html [cited: 4 March 2020].

68. Zhu H, Wang L, Fang $\mathrm{C}$ et al.: Clinical analysis of 10 neonates born to mothers with 2019-nCoV pneumonia. Transl Pediatr 2020; 9: 51-60.

69. Chen $\mathrm{H}$, Guo J, Wang $\mathrm{C}$ et al.: Clinical characteristics and intrauterine vertical transmission potential of COVID-19 infection in nine pregnant women: a retrospective review of medical records. Lancet 2020; 395: 809-815. 